\title{
Autonomeação e autoclassificação na construção de conceitos e classificações sobre gênero, sexualidade e raça no domínio das homossexualidades masculinas
}

\section{Self-naming and self-classification in the concept of concepts and classifications on gender, sexuality and race in the field of male homosexualities}

\author{
Francisco Arrais Nascimento \\ Doutorando em Ciência da Informação pela Universidade Estadual Paulista Júlio de Mesquita Filho \\ (UNESP)
}

\author{
Daniel Martínez-Ávila \\ Professor Permanente do Programa de Pós-Graduação em Ciência da Informação da Universidade \\ Estadual Paulista Júlio de Mesquita Filho (UNESP) \\ Professor Assistente Doutor da Universidad Carlos III de Madrid
}

\begin{abstract}
Resumo: A linguagem enquanto prática de significação, subsidia formas de resistência e linhas de fuga, possibilitando visualizar os processos pelos quais as identidades dos sujeitos são construídas, levando-se a pensar a performatividade exercida pelos sujeitos na construção do Gênero e da Sexualidade. Diante disso, situando-se teórico-metodologicamente em perspectiva discursivo-desconstrucionista, recorrendo aos estudos pós-estruturalistas de base foucaultiana, além da relação com teorizações queer. Tomando-se as sexualidades humanas enquanto cenário, objetivou-se compreender a criação de conceitos e classificações sobre gênero, sexualidade e raça no domínio das homossexualidades masculinas desenvolvida não pela academia, mas sim pelos próprios sujeitos como um ato de autoempoderamento e que influencia de forma direta as representações dos sujeitos, uma vez que se o que fora construído sobre e em torno das homossexualidades alinha-se com a tríade pecado-crime-doença, se faz necessário um rompimento com as linhas componentes do dispositivo de controle social que punem os desvios da norma. Os procedimentos adotados na composição do campo de análise privilegiaram a pesquisa bibliográfica documental associada à análise cultural de produtos advindos de mídias digitais de domínio público. Percebeu-se que no contexto das homossexualidades de maneira geral a linguagem aparece como estratégia de resistência, uma forma de pedagogia difundida entre seus pares, apresentando-se como possibilidade de movimentar-se, criando e recriando formas de se comunicar e expressar-se na dinâmica social, muitas vezes marginalizada e silenciada pelos discursos proferidos por instituições representantes de verdades tidas como absolutas e inquestionáveis.
\end{abstract}

Palavras-chave: Autonomeação. Autoclassificação. Domínio das Homossexualidades. Gênero.

\begin{abstract}
Language as a practice of signification, subsidizes forms of resistance and lines of flight, making it possible to visualize the processes by which the identities of the subjects are constructed, leading to think of the performativity exercised by the subjects in the construction of Gender and Sexuality. Facing this, it is theoretical-methodologically situated in a discursive-deconstructionist perspective, resorting to Foucault's post-structuralist studies, in addition to the relation with queer theorizations. Taking the human sexualities as a scenario, the objective was to understand the creation of concepts and classifications on gender, sexuality and race in the domain of masculine homosexuality developed not by the academy, but by the subjects
\end{abstract}



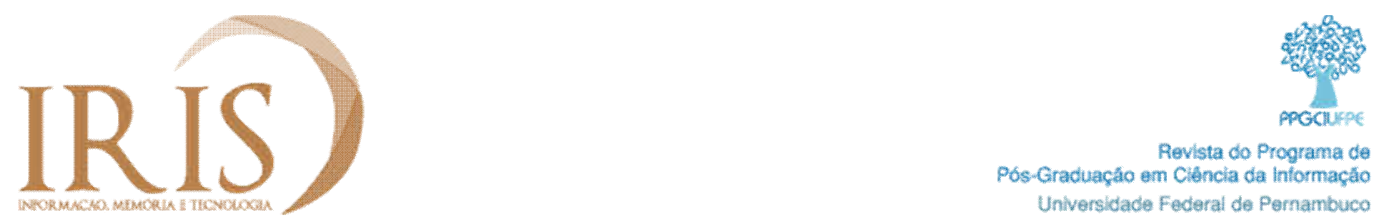

themselves as an act of self-empowerment and that influences in a way direct the representations of the subjects, since if what was built on and around homosexuality aligns itself with the triad sin-crime-disease, a break with the components of the social control device is necessary that punish the deviations of the standard. The procedures adopted in the composition of the field of analysis focused on documentary bibliographic research associated with the cultural analysis of products derived from digital media in the public domain. It was noticed that in the context of homosexuality in general, language appears as a strategy of resistance, a form of pedagogy spread among its peers, presenting itself as a possibility to move, creating and re-creating ways of communicating and expressing itself in the social dynamics, often marginalized and silenced by the discourses uttered by institutions representing truths considered as absolute and unquestionable.

Keywords: Self-naming. Self-classification. Domain of Homosexuality. Gender. Race.

\section{Introdução}

Badinter (1993, p. 29) inaugura um diálogo com Beauvoir (1967) ao afirmar que "[...] o homem não nasce homem, ele se torna homem", assim como "Ninguém nasce mulher: torna-se mulher" (BEAUVOIR, 1967, p. 9). Esse diálogo faz emergir toda uma gama de construtos sociais que tornaram-se subterrâneos (POLLAK, 1989) em função do discurso hegemônico que silencia, apaga e marginaliza toda pratica desviante do padrão "eleito", ou seja, uma "ordem compulsória" (RICH, 1993; BUTLER, 2002) que exige dos sujeitos uma coerência total entre um sexo, um gênero e uma conduta/desejo/afeto, que são obrigatoriamente heterossexuais.

Logo, ao ampliar a interação interseccional de tal diálogo (PISCITELLI, 2008; NOGUEIRA; OLIVEIRA, ALMEIDA, COSTA, 2010; POCAHY, 2013), limitando-se a óptica heteronormativa e reduzindo tal contexto a visão medico científica de cunho biológico, a indagação mais verossimilhante em uma sociedade regida por uma divisão social marcadamente binária e oposicional seria, "O que é o homem?". Diante disso, a resposta mais óbvia sob esse viés seria: aqueles nascidos com cromossomos XY e que deverá se interessar por mulheres, futebol, armas e, no limite, nutrir uma aversão declarada pela cor rosa (HERNANDES, 2019).

Em tempos hodiernos, enquanto fruto de uma "scientia sexualis" que se ancora na compreensão de que "O poder produz saber [...], não há relação de poder sem constituição correlata de um campo de saber, nem saber que não suponha e não constitua ao mesmo tempo relações de poder" (FOUCAULT, 2013, p. 30) emergem discursos outros que responderiam a indagação supra citada como fruto de uma construção social que nada tem de natural ou ainda que seria uma questão de autoafirmação, onde, “[...] homem é quem se diz homem, a despeito tanto de seu fenótipo 
Autonomeação e autoclassificação na construção de conceitos e classificações sobre gênero, sexualidade e raça no domínio das homossexualidades masculinas Francisco Arrais Nascimento e Daniel Martínez-Ávila

quanto das imposições da sociedade" (HERNANDES, 2019, p. 17). O que se pode observar nas três linhas de pensamento apresentadas é que todas se alinham sobre um tom imperativo "deve ser". Tal forma de tentativa de controle se mante por meio da política da coerção que domina o corpo e manipula todos seus movimentos (FOUCAULT, 2013, p. 133), fazendo-se presente nas mais diversas formas em um discurso incessante.

Logo, percebe-se assim, que a coerência do gênero se realiza na criação da ilusão do que seria "natural" para o corpo sexuado e do que pareceria "natural" para aqueles que afirmam ter esse corpo por agirem assim. Revelando-se a intenção de criar corpos sexuados e neles inserir a "natural binaridade" (masculino e feminino), onde ancora-se a gênese de uma realidade baseada na negação, consolidando estereótipos que certificam o padrão heteronormativo de masculinidade e/ou feminilidade (BADINTER, 1993). Em suma, “[...] o gênero não é uma performance que um sujeito anterior elege para realizar, mas o gênero é performativo, no sentido em que constitui como efeito o sujeito que pretendo expressar" (BUTLER, 2007, p. 24). Cabe ressaltar que, tudo o que não é "natural" não é considerado normal pelos especialistas, classificadores, e com isso é alocado além das fronteiras da norma, do padrão, do foco do sistema de organização do conhecimento e é empurrado às margens (OLSON, 1997; CORNELL, 1992).

Bourdieu (1996, p. 87), destaca que “[...] o poder das palavras é apenas o poder delegado do porta-voz"; isso evidencia que o sujeito da fala, na posição social por ele ocupada, fará com que seu discurso seja validado, preservado e disseminado. Moreira (2011, p. 2919) ressalta que no ato de nomear " [...] as posições sociais de quem nomeia e do que é nomeado devem ser obedecidas, e essas posições revelam quem tem poder e autoridade para nomear e quem, ou o que, está subordinado a esse poder".

Inscrito nesse jogo de poder, os conceitos de Gênero e Sexualidade em determinado momento se interseccionam com o marcador de Raça, uma vez que "[...] antes de ser pensada em termos de cultura, ou em termos econômicos, a nação foi pensada em termos de raça" (CORRÊA, 2001). Denizart (1997, p. 9) afirma que “[...] a sexualidade é 'uma fantasia passageira', a ser usufruída como bem a entendemos", mas tal discurso é compreendido sob a óptica social, que concebe que toda construção, seja de um sujeito ou de uma identidade, envolve certo grau de normatização, cujo efeito é a produção de excluídos (MISKOLCI, 2009). Tal compreensão, sob o imperativo do marcador de raça remonta ao período colonial do Brasil e consequentemente as origens do processo de miscigenação no qual a sociedade hipererotizou a figura do corpo negro. 

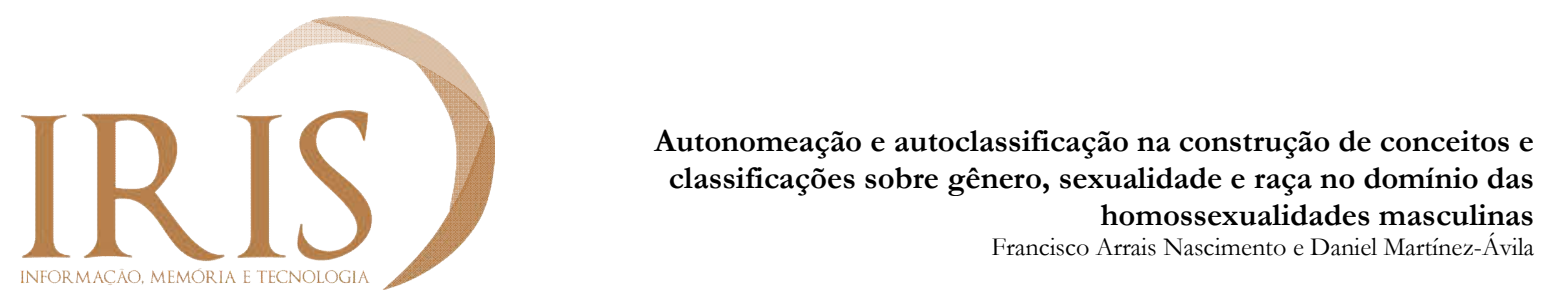

O negro no Brasil não foi apenas a mão de obra escravizada que serviu de lastro para a manutenção da economia escravagista. No âmbito das sexualidades, ocupando zonas de sombra que, apesar de reconhecidas, não auferem o espaço de direito e, em tempos hodiernos, ainda tem sua sexualidade regida por ecos discursivos que têm sua gênese no discurso da norma machista, heteronormativa e escravagista, que aloca o corpo negro na condição de não humano, esvaziando o sujeito de sua natureza e de todos os desejos, inserindo assim no "objeto" a fetichização e certificando a hipererotização do corpo negro em uma reconfiguração do binômio "servilismo" e "prazer".

Diante do que fora exposto, objetivou-se compreender a criação de conceitos e classificações sobre gênero, sexualidade e raça no domínio das homossexualidades masculinas desenvolvida não pela academia, mas sim pelos próprios sujeitos como um ato de autoempoderamento e que influencia de forma direta as representações dos sujeitos.

\section{Aspectos metodológicos}

Utilizou-se enquanto metodologia, uma cartografia de documentos, como forma de reconhecimento do domínio a ser analisado. Segundo Deleuze (1996) a cartografia como um método para além de seus usos limitados dentro da Geografia, onde o autor aloca a mesma como uma alternativa para "desemaranhar" as linhas que compõe um dispositivo, uma vez que o mesmo é compreendido enquanto uma tessitura complexa e embrincada que fora construído e ressignificado no âmbito social sob camadas de construção histórica, como forma de permanência de forma funcional e subserviente na relação de poder/saber (FOUCAULT, 2013). Uma vez que segundo Bourdieu (2002) como se trata de construir e representar uma categoria social dominada, quer dizer, constituída sobre termos negativos em função da transgressão a norma, deve-se levar em consideração que sua representação envolve o rompimento com as categorias de percepção que fundamentam a inferioridade. Esse rompimento permitiria que experiências vividas de forma tácita ou dissimulada ganhassem visibilidade a partir de sua enunciação pública e que se construam em signos de pertencimento a um grupo social, a uma identidade. Ressalta-se que,

[...] o dispositivo, portanto, está sempre inscrito em um jogo de poder, estando sempre, no entanto, ligado a uma ou a configurações de saber que dele nascem, mas que igualmente o 

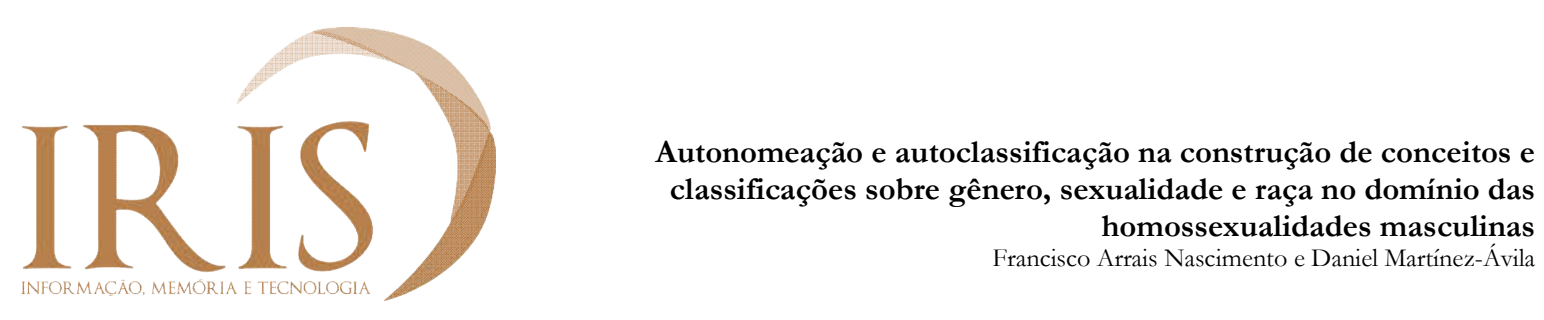

condicionam. É isto, o dispositivo: estratégias de relações de força sustentando tipos de saber e sendo sustentadas por eles. (FOUCAULT, 2000, p. 246).

Logo,

[...] desemaranhar as linhas de um dispositivo é, em cada caso, traçar um mapa, cartografar, percorrer terras desconhecidas, é o que Foucault chama de 'trabalho de terreno'. É preciso instalarmo-nos sobre as próprias linhas, que não se contentam apenas em compor um dispositivo, mas atravessam-no, arrastam-no, de norte a sul, de leste a oeste ou em diagonal (DELEUZE, 1996, p. 1).

Assim, a cartografia documental alicerçou o estudo de forma a favorecer subsídios necessários ao levantamento das nomenclaturas empregadas pelos sujeitos que se encontram no desvio da norma, ancorando-se em bases teóricas consistentes com anteriores estudos de representações de desejo queer em aplicativos e sites online (KEILTY, 2012a; 2012b; 2013; 2017).

Em um primeiro momento utilizou-se do arcabouço teórico da Organização do Conhecimento, amparando a pesquisa sob as contribuições de (KEILTY, 2010; SCHALLER, 2011; ANDRÉS-VÁSQUEZ \& GONZÁLEZ-TERUEL, 2015) no tocante aos estudos das comunidades usuárias acerca do comportamento e a suas necessidades de informação. Para além do ancoramento nos estudos de natureza cultural e ética do campo da organização do conhecimento, voltados para questões sobre a multiculturalidade, a inclusão, o respeito à diversidade e outros (BEGHTOL, 2002 a,b; GARCÍA-GUTIÉRREZ, 2002; PINHO, 2006) em consonância com os estudos de análise de domínio (HJØRLAND, ALBRECHETSEN, 1995; HJØRLAND, 1997; 2002; 2003; TENNIS, 2012) e dos estudos de (OLSON, 1997; 2002; DE LA TIERRA, 2008; CAMPBELL; GUIMARÃES; PINHO; MARTÍNEZ-ÁVILA; NASCIMENTO, 2017) acerca do poder do indexador e dos estudos terminológicos sobre o domínio LGBTQI+ em profícuo diálogo com as contribuições de (ALLPORT, 1954; BERMAN, 1993) em suas respectivas contribuições acerca da formação, consolidação e ação do preconceito, da discriminação e das antipatias.

Em um segundo momento realizou-se a coleta da amostra que compusera o corpus do estudo, a mesma foi realizada no período de outubro de 2018 a março de 2019, apresentando como amostra um total de 2.505 perfis em dois aplicativos mobile de interação afetivo sexual distribuídos da seguinte forma: 1.732 palavras extraídas de 1.005 títulos de perfis de usuários do aplicativo Scruff e 2.241 palavras extraídas de 1.500 perfis de usuários do aplicativo Grindr. Cabe ressaltar que o funcionamento de ambos os aplicativos são semelhantes fazendo uso de geolocalização, no entanto 
Autonomeação e autoclassificação na construção de conceitos e classificações sobre gênero, sexualidade e raça no domínio das homossexualidades masculinas Francisco Arrais Nascimento e Daniel Martínez-Ávila

o Grindr apresenta uma limitação do alcance espacial de recuperação de perfis, o mesmo não ocorre com o Scruff. Para sanar tal limitação foram coletados perfis em diversas localidades visando aumentar a abrangência do estudo.

Enquanto técnica empregada para tratamento da amostra utilizou-se da mineração de textos por meio do softwere Wordcounter (https://wordcounter.net/), permitindo a melhor visualização do conteúdo coletado e possibilitando assim o processo de análise de conteúdo (BARDIN, 2011). Ressalta-se que o estudo aqui apresentado é um desdobramento de um estudo acerca das representações no domínio das homossexualidades com ênfase nos fenômenos de autonomeação e autoclassificação dos sujeitos enquadrados no desvio da norma.

\section{Resultados e discussões}

Ao imergir no domínio das homossexualidades é necessário observar a sexualidade humana não enquanto apenas uma prática, uma forma de desejo polimorfa e multifacetada ou um afeto que não se baliza unicamente pelos padrões éticos e morais constituídos pela sociedade, mas como um domínio plural e volátil, dadas as suas multifacetadas manifestações e representações. Segundo a construção sócio dinâmica acerca das masculinidades vigentes no sistema heteronormativo balizadas por padrões machistas oriundos do patriarcado, o sujeito "homem” segundo tal construção é aquele que "come", ou seja, que penetra com seu falo não apenas mulheres mas também outros homens, que por meio da hierarquização das masculinidades apresentadas por Cecchetto (2004) e Connell (2005), são categorizados como "bichas", "baitolas", "frangos" entre outros, cabendo ressaltar que aqueles que apresentam características do sexo aposto são diminuídos do ponto de vista social, sendo oprimidos e excluídos do círculo da legitimidade das masculinidades. Dreyfus e Rabinow (2010, p.243) observam que “[...] o poder não está restrito às instituições políticas. O poder representa um papel diretamente produtivo, ele vem de baixo, é multidirecional funcionando de cima para baixo e também de baixo para cima". Logo, o discurso centro-margem que marginaliza, certifica a inadequabilidade dos sujeitos frente ao imposto pela norma é replicado e ecoa nas margens da sociedade instaurando hierarquias de valor simbólico. Diante disso, se pode vislumbrar que algumas peculiaridades apontadas por Amorós (1991) que emergem do domínio das homossexualidades e que dificilmente podem ser observadas por um olhar centro-margem. 
O oprimido parece estar condenado a não saber de si mesmo senão sob a forma de falsa consciência. Por sua vez, a falsa consciência, em qualquer de suas formas - mistificação, ambiguidade, reconciliações ilusórias, autocomplacência narcisista - é a cumplicidade mais eficaz e profunda que pode encontrar um sistema de dominação. Todo sistema de dominação sabe bem como formular os termos do insolúvel dilema do oprimido: suas reivindicações de igualdade serão irremissivelmente reconduzidas à integração no sistema; suas reivindicações radicais de diferença a condenarão à irremissível marginalização (AMORÓS, 1991, p. 72).

Amorós (1991) lança luz sobre zonas de sombra da sociedade fazendo com que contornos de sujeitos e compreensões acerca deles sejam reveladas. Butler (2007) afirma que aqueles que não se adequam a essa ordem (heteronormatividade) são alocados na zona de exclusão, tornando-se ininteligíveis como pessoa porque a identidade só pode ser estabelecida dentro das "[...] leis que buscam estabelecer as linhas causais ou expressivas de conexão entre sexo biológico, gêneros constituídos culturalmente e a 'expressão' ou 'efeito' de ambos nas manifestações do desejo sexual nas práticas sexuais" (BUTLER, 2007, p. 72).

Butler (2002) define tais sujeitos como corpos abjetos, aqueles cujas vidas são consideradas ilegítimas e, portanto, quase impossíveis de se materializar, destacando ainda que o corpo abjeto “[...] não se restringe de modo algum a sexo e a heteronormatividade. Relaciona-se a todo tipo de corpos cujas vidas não são consideradas, vidas" e “[...] cuja materialidade é entendida como, não importante” (PRINS; MEIJER, 2002, p. 161). Assim, compreende-se que toda política identitária é "anti-diversitária", uma vez que a identidade não apenas não comporta, mas sim segrega toda e qualquer singularidade, "minoritiza" nos sistemas de classificação, em palavras de Campbell (2000). Logo, toda diferença é uma (des)identidade, uma vez que, ou o sujeito adota a moral da identidade ou a ética da diferença.

Tal forma de hierarquização de cunho estereotipada (ALBUQUERQUE JR., 2010), faz com que aqueles que não desempenham a função ativa, sejam envoltos em um contexto de embaraço e vergonha não apenas aos sujeitos que assim são, mas para todos aqueles que apresentam algum tipo de relação com o mesmo, seja essa relação de natureza fraterna ou mesmo afetivo sexual, subjugando esse sujeito a condição de inferior na hierarquia das masculinidades impostas socialmente, e que arraigam seus discursos na esfera machista, heteronormativa e patriarcal vigente. Essa afirmação pode ser observada nas nomenclaturas adotadas pelos sujeitos ao nomear seus perfis nos aplicativos de interação afetivo sexual além do conteúdo das descrições e interesses onde se pode perceber certa negação, aversão a sujeitos que apresentam tal posição nas manifestações de 
Autonomeação e autoclassificação na construção de conceitos e classificações sobre gênero, sexualidade e raça no domínio das homossexualidades masculinas Francisco Arrais Nascimento e Daniel Martínez-Ávila

desejo/prazer. Tal afirmação pode ser comprovada ao visualizar a mineração de texto representada nas Figuras 1 e 2.

Figura 1 - Densidade dos termos segundo sua composição

\begin{tabular}{|c|c|c|c|c|c|}
\hline \multicolumn{2}{|c|}{ Keyword Density $\underline{x 1} \underline{\times 2} \underline{\times 3}$} & Keyword Den & $\checkmark$ & \multicolumn{2}{|c|}{ C Keyword Density $\underline{x 1} \underline{x 2} \underline{x 3}$} \\
\hline discreto & $402(25 \%)$ & passivo discreto & $19(4 \%)$ & nāo curto afeminado & $8(4 \%)$ \\
\hline urso & $139(9 \%)$ & macho discreto & $18(4 \%)$ & passivo não afeminado & $4(2 \%)$ \\
\hline afeminado & $71(4 \%)$ & discreto afim & $14(3 \%)$ & discreto de boa & $3(2 \%)$ \\
\hline brotheragem & $68(4 \%)$ & nāo curto & $10(2 \%)$ & ativo discreto dotado & $2(1 \%)$ \\
\hline bear & $66(4 \%)$ & nāo afeminado & 9(2\%) & atv namoro discreto & 2(1\%) \\
\hline sigilo & $43(3 \%)$ & ativo discreto & $9(2 \%)$ & casal de ursos & $2(1 \%)$ \\
\hline passivo & $43(3 \%)$ & atv discreto & $9(2 \%)$ & homem psv discreto & 2(1\%) \\
\hline macho & $38(2 \%)$ & de boa & $8(2 \%)$ & não curto afeminados & $2(1 \%)$ \\
\hline ativo & $32(2 \%)$ & discreto sigilo & $8(2 \%)$ & partenon nâo afeminado & $2(1 \%)$ \\
\hline atv & $31(2 \%)$ & curto afeminado & $8(2 \%)$ & passivo discreto com & $2(1 \%)$ \\
\hline
\end{tabular}

Fonte: Elaborado pelos autores a partir dos dados coletados nos perfis do aplicativo Scruff, 2019.

\begin{tabular}{|c|c|c|c|c|c|}
\hline \multicolumn{6}{|c|}{ Figura 2 - Densidade dos termos segundo sua composição } \\
\hline \multicolumn{2}{|c|}{ Keyword Density } & \multicolumn{2}{|l|}{ Keyword Density } & \multicolumn{2}{|l|}{ Keyword Density } \\
\hline discreto & $414(20 \%)$ & passivo discreto & $33(7 \%)$ & ativo discreto dotado & $2(2 \%)$ \\
\hline urso & $143(7 \%)$ & hetero flexivel & $26(5 \%)$ & homem passivo discreto & $2(2 \%)$ \\
\hline afeminado & $87(4 \%)$ & ativo discreto & $18(4 \%)$ & passivo discreto local & $2(28)$ \\
\hline passivo & $79(48)$ & macho discreto & $18(4 \%)$ & ativo discreto broder & $1(1 \%)$ \\
\hline ativo & $74(4 \%)$ & passivo afeminado & $16(3 \%)$ & ativo namoro discreto & $1(1 \%)$ \\
\hline brotheragem & $71(3 \%)$ & discreto afim & $13(3 \%)$ & bear forever brasil & $1(1 \%)$ \\
\hline bear & $70(3 \%)$ & discreto ativo & $12(3 \%)$ & bear gouinebear guy & $1(1 \%)$ \\
\hline sigilo & $68(3 \%)$ & curto afeminado & $11(2 \%)$ & bear itu $s p$ & $1(1 \% 6)$ \\
\hline homem & $56(3 \%)$ & discreto sigilo & $10(2 \%)$ & bear top chasers & $1(1 \%)$ \\
\hline macho & $41(24)$ & bear ativo & $8(2 \%)$ & beard ginger love & $1(156)$ \\
\hline
\end{tabular}

Fonte: Elaborado pelos autores a partir dos dados coletados nos perfis do aplicativo Grindr, 2019.

Diante do que foi recuperado no tratamento dado aos termos e no conteúdo oriundo dos perfis se pode vislumbrar que a autoclassificação e a autonomeação dos sujeitos ancoram-se sob o viés das masculinidades "Macho", "Ativo", "Homem”, "Urso", "Ativo", "Hetero" o que faz com que em uma primeira observação se vislumbre a aversão a qualquer identificação com o segmento da população composto por Lésbicas, Gays, Bissexuais, Travestis, Transexuais, Intersexuais, Pessoas em inconformidade com o gênero e praticantes de modalidades alternativas de sexualidades (LGBTQI), mesmo estando alocados sob uma lógica desviante devido a orientação do desejo/afeto. 
Desse modo, se no mundo virtual cria-se um espectro, uma performance que se ancora no desejo, desejo esse em muitos aspectos balizados por padrões que tem sua gênese na norma vigente, onde tal entendimento engloba uma compreensão de si, onde “[...] compreender a si mesmo e [...] arquitetar a sociabilidade através da compatibilidade afetiva" (ILLOUZ, 2011, p. 110) é um elemento essencial, uma vez que "[...] a vigilância e a censura da sexualidade orientam-se, fundamentalmente, pelo alcance da "normalidade" (LOURO, 2010, p. 80). Logo, "[...] o segredo ainda parece para muitas pessoas uma estratégia para viver seu desejo" (PELÚCIO; DUQUE, 2010, p. 10). Pelúcio e Duque (2010) tocam em uma segunda instancia de autonomeação recorrente na amostra, termos como "Sigilo", "Discreto", "Fora do meio" e suas variações emergem de forma contundente do universo analisado certificando as zonas de sombra nas quais as manifestações identitárias desviantes da norma eleita foram alocadas.

Segundo Guattari e Rolnik (1996),

[...] vemo-nos solicitados o tempo todo e de todos os lados a investir a poderosa fabrica serializada, produtora destes homens que somos, reduzidos à condição de suporte de valor - e isso até (e sobretudo) quando ocupamos os lugares mais privilegiados na hierarquia dos valores. Tudo leva a esse tipo de economia. Muitas vezes não há outra saída. É que quando na desmontagem, perplexos e desparamentados, nos fragilizamos, a tendência é adotar posições meramente defensivas. Por medo da marginalização na qual corremos o risco de ser confinados quando ousamos criar qualquer território singular, isto é, independente das serializações subjetivas; por medo de essa marginalização chegar a comprometer até a própria possibilidade de sobrevivência (o que é plenamente possível), acabamos reivindicando um território no edifício das identidades reconhecidas. Tornamo-nos assim muitas vezes em dissonância com nossa consonância - produtores de algumas sequencias da linha de montagem do desejo (GUATTARI e ROLNIK, 1996, p. 12).

Cecchetto (2004) aponta que,

[...] a masculinidade hegemônica é definida como um modelo central, o que implica considerar outros estilos como inadequados e ou inferiores. Isso abre caminho para uma abordagem mais dinâmica da masculinidade: a divisão crucial entre uma masculinidade hegemônica e várias subordinadas que lhe servem de contraponto e antiparadigma (CECCHETTO, 2004, p. 63).

Isto posto, compreende-se que a sexualidade e a própria construção social do sexo configuram-se como dispositivos disciplinares e biopolíticos que se instauram enquanto técnicas políticas necessárias para o governo das massas, ajustando-as à dinâmica da produção e do consumo em ascensão na sociedade regida sob o sistema econômico capitalista, onde a vida "[...] só é útil porque é, ao mesmo tempo, sã e dócil, ou seja, medicalizada e disciplinarizada" (REVEL, 2006, p. 55-56). Revela-se, assim, a tentativa de dominar os sujeitos, tornando-os politicamente dóceis e economicamente produtivos, inscritos em uma dinâmica de poder que se arraiga em um conjunto de 


\section{IRIS}

Autonomeação e autoclassificação na construção de conceitos e classificações sobre gênero, sexualidade e raça no domínio das homossexualidades masculinas Francisco Arrais Nascimento e Daniel Martínez-Ávila

"dispositivos" que suscitam a percepção de discursos hegemônicos que regulam, instauram normas e produzem "verdades", prevalecendo e sendo perpetuados (FOUCAULT, 2000).

Alguns termos identificados na amostra "Urso", "Bear", "Lontra" remontam a segunda metade do século XX, quando Mazzei (1979) esboçou uma classificação bem-humorada estabelecendo os sete arquétipos de animais gays que se tornariam a base do atual "reino animal gay", aproximando os sujeitos de animais a partir de características físicas e comportamentais (Figura 3), classificação essa que insurge no âmbito do domínio LGBTQI+ como uma forma de resistência aos padrões estabelecidos pela própria comunidade LGBTQI+ que apresentava proselitismos por “jovens, sarados e platinados”, estabelecendo no esfera da margem um grau de marginalização ainda maior para aqueles que não se adequavam ao que fora eleito como modelo.

Figura 3 - Classificação do Domínio das Homossexualidades segundo Mazzei (1979)

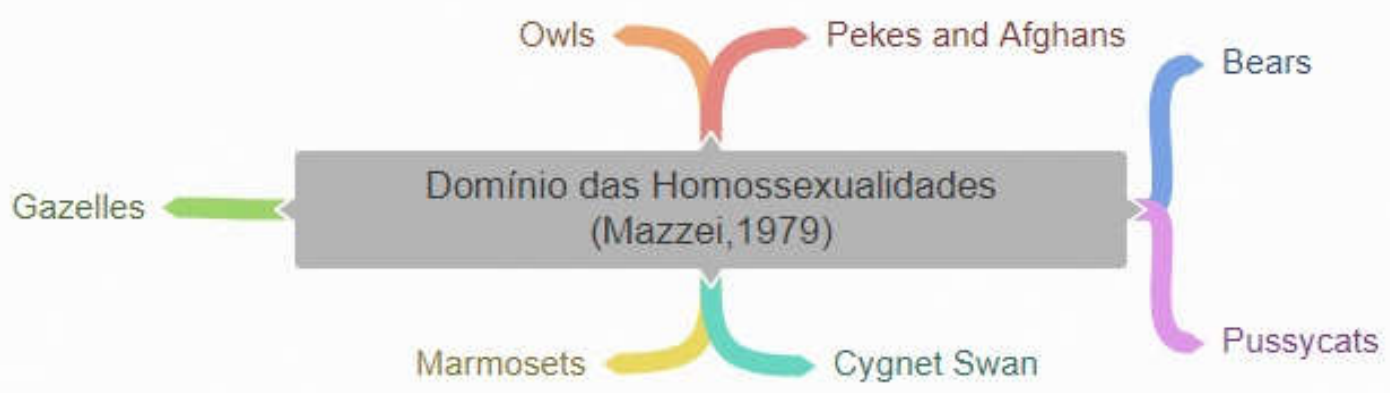

Fonte: Adaptado de Mazzei (1979).

Em tempos hodiernos essa classificação foi modificada, ampliada e ressignificada em muitos aspectos, fazendo surgir subcategorias que aparecem no corpus da pesquisa e lançam luz sobre zonas de sombra (Figura 4). A exemplo do que está sendo colocado a categoria "Urso" (Bear) enquadram-se em um primeiro momento nessa categoria homens, masculinos (heteronormativos), gordos, musculosos, que apresentam pelos corporais e que normalmente eram oriundos de funções laborativas ligadas a construção civil, esportes de força entre outros. 


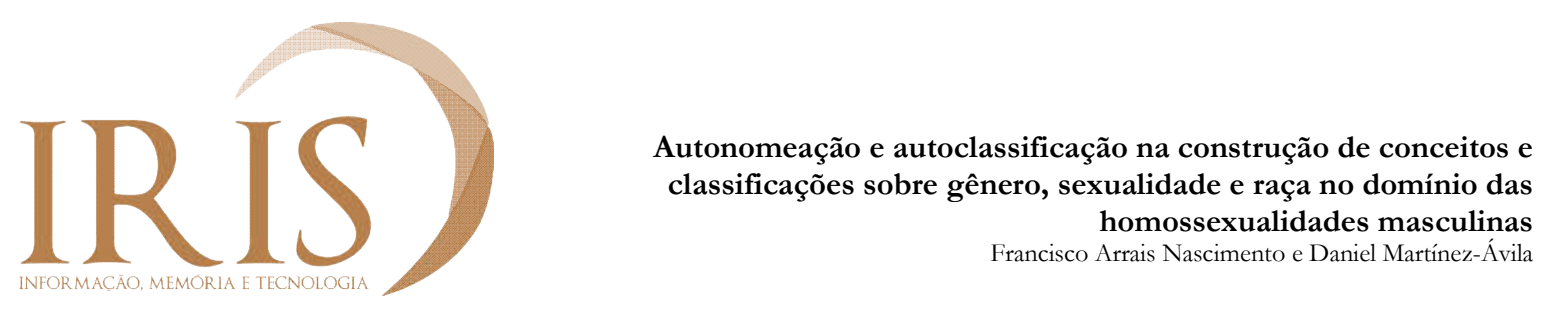

Figura 4 - Classificação do universo ursino

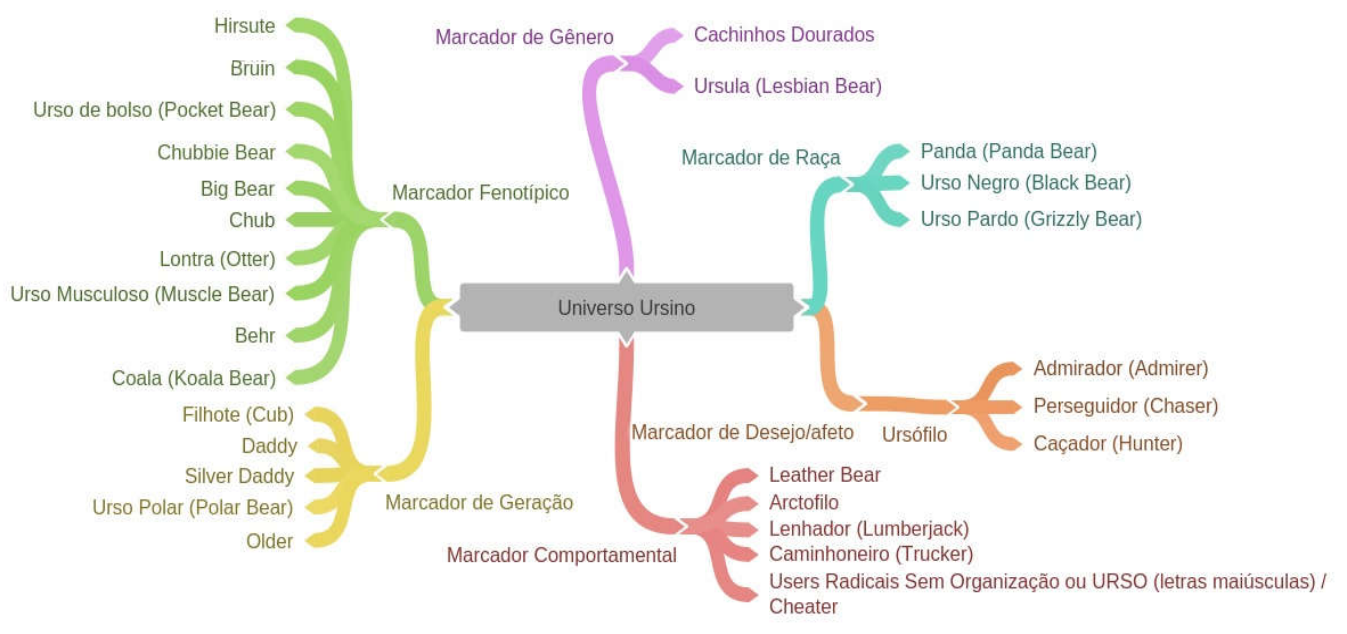

Fonte: Elaborado pelos autores a partir das nomenclaturas encontradas no corpus da pesquisa, 2019.

Ao se autoidentificarem criando classificações, conceitos, nomenclaturas nos aplicativos mobile, o "poder de nomear" do indexador (OLSON, 2002) é vivificado, refletindo estruturas de valores, impostos pela norma e também formas de resistência tanto em um discurso margem-centro, como também em um discurso de autoafirmação em um discurso margem-margem.

A identidade é sempre um processo, nunca estando completa, pois se encontra em constante disputa, forjada no âmago de tensões e representações, moldada por discursos e interesses (HALL, 1999). Ou seja, o uso de termos "desviantes" por parte dos sujeitos que se autonomeiam no aplicativo objetiva uma aceitação social, em um processo no qual a identidade individual molda-se para ser assimilada pela identidade coletiva.

O marcador de raça na pesquisa pode ser visualizado em termos como "Negão da Piroca", "Moreno Dotado", "Negro Dotado”, "Mulato" e suas variações. Nesse interim ao compreender a formação cultural do Brasil pode-se visualizar que a gênese de tais entendimentos heteronormativos, falocentricos e racistas tem sua origem no Brasil colonial, onde o corpo negro mercantilizado pelo sistema escravagista impulsionou não apenas a economia de pedras preciosas, cafeeira e canavieira, mas foi essencial para o processo de miscigenação observado no país.

Diante disso, novas indagações emergem sendo "O que é o negro?" a mais complexa e contundente pois o corpo negro não sofrera apenas suplício físico, mas sim o suplício sob o entendimento foucaultiano enquanto "Pena corporal, dolorosa, mais ou menos atroz [...] é um 

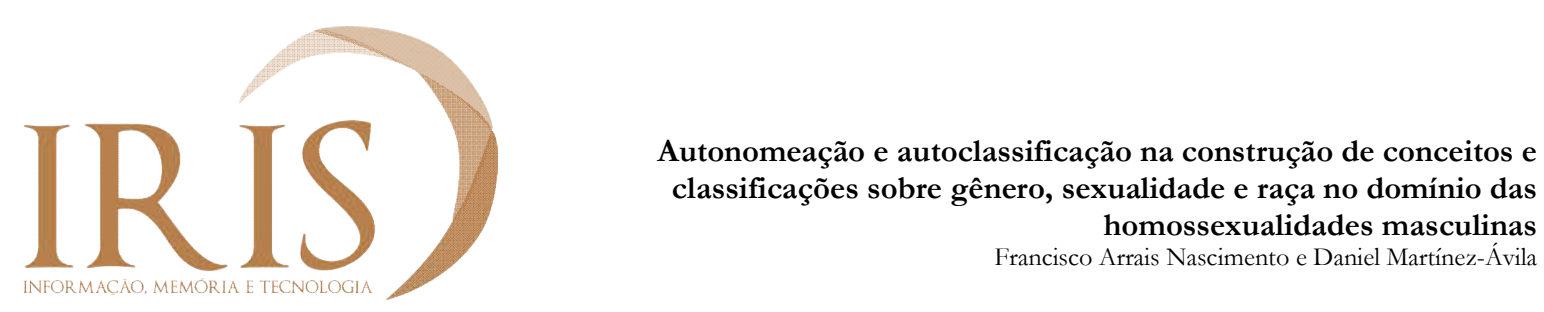

fenômeno inexplicável a extensão da imaginação dos homens para a barbárie e crueldade" (FOUCAULT, 2013, p.35), onde a própria divisão de gênero marcara de forma única a configuração da ação do dispositivo de soberania (FOUCAULT, 2013). Logo, o silenciamento e consequentemente o apagamento fez com que o corpo negro fosse e ainda continue sendo violentamente utilizado sob o viés da hipererotização do corpo em uma reconfiguração do binômio "servilismo" e "prazer". Tal afirmação se aclara quando se volta para as autonomeações que os sujeitos praticam, onde a forma de existência dominante é a do sujeito ativo, dotado de um falo maior que a média e fogoso, removendo-se qualquer outra característica possível de ser observada para além de tal construção histórica.

\section{Considerações finais}

Após o termino da análise dos dados coletados no decorrer do estudo aqui apresentado, percebeu-se que no contexto das homossexualidades de maneira geral a linguagem aparece como estratégia de resistência, uma forma de pedagogia difundida entre seus pares, apresentando-se como possibilidade de movimentar-se, criando e recriando formas de se comunicar e expressar-se na dinâmica social, muitas vezes marginalizada e silenciada pelos discursos proferidos por instituições representantes de verdades tidas como absolutas e inquestionáveis. Ressalta-se ainda que a nomeação e a classificação exercida pelos sujeitos apresentam ecos discursivos marcadamente construídos pela norma e que persistem sendo vivificados e influenciando as margens em discursos que tem sua gênese na norma e consequentemente faz uso de dispositivos de poder e coerção social com o objetivo de manter o poder e o controle das massas.

\section{Financiamento}

Conselho Nacional de Desenvolvimento Científico e Tecnológico - CNPq

\section{Referências}

ALBUQUERQUE JR., Durval Muniz de. A invenção do Nordeste e outras artes. 4. ed. São Paulo: Cortez, 2010.

ALLPORT, W. Gordon. La naturaleza del prejuicio. Buenos Aires: Editorial Universidade de Buenos Aires, 1954. 
Autonomeação e autoclassificação na construção de conceitos e classificações sobre gênero, sexualidade e raça no domínio das homossexualidades masculinas Francisco Arrais Nascimento e Daniel Martínez-Ávila

AMORÓS, Celia. Hacia una crítica de la razón patriarcal. 2. ed. Barcelona: Anthropos, 1991.

ANDRÉS-VÁZQUEZ, Tabatha; GONZÁLEZ-TERUEL, Aurora Information behaviour of lesbian, gay, bisexual and transsexual (LGBT)., 2015 . In LGBTQI Empowering Realities. Challenging homophobia \& transphobia, Torino (Italy), Februaru, 2015. [Conference paper]

BADINTER, Elisabeth. XY: sobre a identidade masculina. Rio de Janeiro: Ed. Nova Fronteira. 1993.

BARDIN, Laurence. Análise de Conteúdo. Lisboa: Edições70. 2011.

BEAUVOIR, Simone de. O segundo sexo: a experiência vivida. 2 ed. São Paulo: Difusão Européia do Livro, 1967.

BEGHTOL, C. A proposed ethical warrant for global knowledge representation and organization systems. Journal of Documentation, London, v. 58, n. 5, p. 507-532, 2002a.

BEGHTOL, C. Universal concepts, cultural warrant, and cultural hospitality. In: López-Huertas, M. J. (Ed.). Challenges in knowledge representation and organization for the 21st century: integration of knowledge across boundaries. Würzburg: ERGON, 2002b. p. 45-49.

BERMAN, Sanford. Prejudice and antipathies: a tract on the LC subject heads concerning people. Jefferson: McFarland \& Company Inc. Publishers. 1993.

BOURDIEU, Pierre. A economia das trocas linguísticas: o que falar quer dizer. São Paulo: EDUSP, 1996.

BOURDIEU, Pierre. A Dominação Masculina. Rio de Janeiro: Bertrand Brasil, 2002.

BUTLER, Judith P. Cuerpos que importam: sobre os limites materiais e discursivos do sexo. Buenos Aires: Paidós. 2002.

BUTLER, Judith P. El género en disputa. El feminismo y la subversión de la identidad. Barcelona: Paidós. 2007.

CAMPBELL, D. Grant. Queer theory and the creation of contextual subject access tools for gay and lesbian communities. Knowledge organization, v. 27, p. 122-131, 2000.

CAMPBELL, D. Grant; GUIMARÃES, José Augusto Chaves; PINHO, Fabio Assis; MARTÍNEZ-ÁVILA, Daniel; NASCIMENTO, Francisco Arrais. The Terminological Polyhedron in LGBTQ Terminology: SelfNaming as a Power to Empower in Knowledge Organization. Knowledge Organization, v. 44, n. 8, p. 586591. 2017.

CECCHETTO, Fátima Regina. Violência e estilos de masculinidade. Rio de Janeiro: Editora da FGV, 2004.

CONNELL, Raewyn William. Masculinities. 2end ed. Berkeley and Los Angeles, California: University of California Press, 2005.

CORNELL, Drucilla. The philosophy of the limit. New York: Routledge, 1992. 
Autonomeação e autoclassificação na construção de conceitos e classificações sobre gênero, sexualidade e raça no domínio das homossexualidades masculinas Francisco Arrais Nascimento e Daniel Martínez-Ávila

CORRÊA, Mariza. As ilusões da liberdade: A escola Nina Rodrigues e a antropologia no Brasil. Bragança Paulista: Editora da Universidade São Francisco, 2001.

DE LA TIERRA, T. Latina lesbian subject headings: the power of naming. In: ROBERTO, K. R. Radical Cataloging: Essays at the Front. Jefferson: McFarland \& Company, 2008. p. 94-102.

DELEUZE, Gilles. O que é dispositivo? In: DELEUZE, Gilles. O mistério de Ariana. Lisboa: Passagens, 1996.

DENIZART, Hugo. Engenharia erótica: travestismo. Rio de Janeiro: Jorge Zahar. 1997.

DREYFUS, Hubert; RABINOW, Paul. Michel Foucault, uma trajetória filosófica (para além do estruturalismo e da hermenêutica). Rio de Janeiro: Forense Universitária, 1995.

FOUCAULT, Michel. Sobre a história da sexualidade. Rio de Janeiro: Graal. 2000.

FOUCAULT, Michel. Vigiar e punir: história da violência nas prisões. 41.ed. Petrópolis: Vozes, 2013.

GARCÍA GUTIÉRREZ, A. Knowledge organization from a "culture of the border": towards a transcultural ethics of mediation. In: LÓPEZ-HUERTAS, M. J. (Ed.). Challenges in knowledge representation and organization for the 21st century: integration of knowledge across boundaries. Würzburg: ERGON-Verlag, 2002. p. 516-522.

GUATTARI, Felix; ROLNIK, Suely. Micropolítica: cartografias do desejo. Petrópolis: Vozes. 1996.

HALL, Stuart. A identidade cultural na pós-modernidade. 3. ed. Rio de Janeiro: DP\&A. 1999.

HERNANDES, Rony. Cartografias da masculinidade - Do mito aos horizontes de desconstrução. Revista Cult. São Paulo, n. 242, p.17-35, fevereiro, 2019.

HJØRLAND, B.; ALBRECHTSEN, H. Toward a new horizon in information science: domain-analysis. Journal of the American Society for Information Science, Washington, v. 46, n. 6, p. 400-425, 1995.

HJØRLAND, B. Information seeking and subject representation: an activity theoretical approach to Information Science. London: Greenwood Press, 1997.

HJØRLAND, B. Domain analysis in information science: eleven approaches - traditional as well as innovative. Journal of Documentation, London, v. 58, n. 4, p. 422-462, 2002.

HJØRLAND, B. Fundamentals of knowledge organization. Knowledge Organization, Würzburg, v. 30, n. 2, p. 87-111, 2003.

ILLOUZ, E. O amor nos tempos do capitalismo. Rio de Janeiro: Zahar. 2011.

KEILTY, Patrick. Lesbian, gay, bisexual, and transgender information needs. Encyclopedia of Library and Information Sciences, v. 3, p. 3275-3280, 2010.

KEILTY, Patrick. Tagging and Sexual Boundaries. Knowledge Organization, v. 39, n. 5, p. 320-324. 2012a. 
Autonomeação e autoclassificação na construção de conceitos e classificações sobre gênero, sexualidade e raça no domínio das homossexualidades masculinas Francisco Arrais Nascimento e Daniel Martínez-Ávila

KEILTY, Patrick. Sexual Boundaries and Subcultural Discipline. Knowledge Organization, v. 39, n. 6, p. 417-431. 2012b.

KEILTY, Patrick. Super Tagging in the Development of Sexual Nomenclature and Social Organization Online. Advances In Classification Research Online, v. 23, n. 1, p. 17-20. 2013.

KEILTY, Patrick. Carnal Indexing. Knowledge Organization, v. 44, n. 4, p. 265-272, 2017.

LOURO, Guacira Lopes. Gênero, sexualidade e educação: uma perspectiva pós estruturalista. 11. ed. Petrópolis: Vozes. 2010.

MAZZEI, George. Who's Who in the Zoo?. The Advocate. p. 42-43. 1979.

MISKOLCI, Richard. O armário ampliado: notas sobre sociabilidade homoerótica na era da internet. Revista Gênero, v. 9, n. 2, p. 171-190. 2009.

MOREIRA, Thami Amarílis Straiotto. O ato de nomear- da construção de categorias de gênero até a abjeção. In: XIV CONGRESSO NACIONAL DE LINGUÍSTICA E FILOLOGIA, 2010. Anais... Rio de Janeiro. v. XIV, n. 4, tomo 4, 2011. p. 2914-2926. ISSN 1519-8782.

NOGUEIRA, Conceição; OLIVEIRA, João Manuel de; ALMEIDA, Miguel Vale de; COSTA, Carlos Gonçalves; RODRIGUES, Liliana; PEREIRA, Miguel. Estudo sobre a discriminação em função da orientação sexual e da identidade de género. Lisboa: Comissão para a Cidadania e a Igualdade de Género, 2010.

OLSON, Hope A. The Feminist and the Emperor's New Clothes: Feminist Deconstruction as a Critical Methodology for Library and Information Studies. Library \& Information Science Research, v. 19, n. 2, p. 181-198, 1997.

OLSON, Hope A. The power to name: locating the limits or subject representation in libraries. Dordrecht: Kluwer Academic Publisher. 2002.

PELÚCIO, Larissa; DUQUE, Tiago. Homossexualidades, estigmas e o discurso preventivo às DST/AIDS no Brasil ou como os gays deixaram de ser homens que fazem sexo com homens. Anais Seminário Internacional Fazendo Gênero, Florianópolis, SC, Brasil. 2010.

PINHO, Fabio Assis. Aspectos éticos em representação do conhecimento: em busca do diálogo entre Antonio García Gutiérrez, Michèle Hudon e Clare Beghtol. 2006. 123 f. Dissertação (Mestrado em Ciência da Informação) - Faculdade de Filosofia e Ciências, Universidade Estadual Paulista, Marília.

PISCITELLI, Adriana. Interseccionalidade, categorias de articulação e experiências de migrantes brasileiras. Revista Sociedade e Cultura, v. 11, n. 2, p. 263-274, jul./dez. 2008.

POCAHY, Fernando Altair. Interseccionalidade: uma prática-teorização feminista possível na "era pósgênero"? In: DORNELLES, Priscila G.; WENETZ, Ileana; SCHWENGBER, Simone V. (org.). A Educação Física em diálogo com os Estudos Feministas. Ijuí: Unijuí, 2013.

POLLAK, Michael. Memória, esquecimento, silêncio. Revista Estudos Históricos, Rio de Janeiro, v. 2, n. 3, p. 3-15, jun. 1989. 


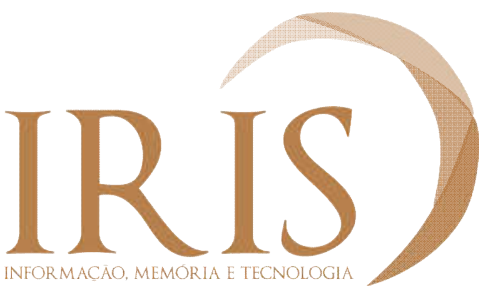

Autonomeação e autoclassificação na construção de conceitos e classificações sobre gênero, sexualidade e raça no domínio das homossexualidades masculinas Francisco Arrais Nascimento e Daniel Martínez-Ávila

PRINS, Baukje; MEIJER, Irene Costera. Como os corpos se tornam matéria: entrevista com Judith Butler. Revista Estudos Feministas, v. 10, n. 1, p. 155-167. 2002.

REVEL, J. (2006). Nas origens do biopolítico: de Vigiar e punir ao pensamento da atualidade. In: J. Gondra. \& W. Kohan (org.), Foucault 80 anos (pp. 51-62). Belo Horizonte: Autêntica. 2006.

RICH, Adrienne. Compulsory heterosexuality and lesbian existence. In: B. C. Gelp, \& A. Gelp (ed.). Adrienne Rich's Poetryand Prose. New York/London: W.W. Norton \& Company. 1993.

SCHALLER, S. Information Needs of LGBTQ College Students. Libri, v. 61, n. 2, 100, 2011.

TENNIS, J. A convenient verisimilitude or oppressive internalization? Characterizing the ethical arguments surrounding hierarchical structures in knowledge organization systems. Knowledge Organization, Würzburg, v. 39, n. 5, p. 394-397, 2012.

Data de submissão: 03 de outubro de 2019.

Data de aceitação: 26 de dezembro de 2019. 